\title{
POŚREDNICY KULTUROWI I ICH ROLA W GOSPODARCE KREATYWNEJ
}

KRZYSZTOF STACHOWIAK

Instytut Geografii Społeczno-Ekonomicznej i Gospodarki Przestrzennej UAM

Institute of Socio-Economic Geography and Spatial Management, Adam Mickiewicz University in Poznań

krst@amu.edu.pl

\section{WPROWADZENIE - PODMIOTY GOSPODARKI KREATYWNEJ}

Gospodarka kreatywna jest tą częścią systemu gospodarczego, której rozwój dokonuje się pod dominującym wpływem kultury i jej zasobów. Dobra powstające w takiej gospodarce, które można określić jako dobra kreatywne, charakteryzują się relatywnie wysoką wartością kulturową, ale także posiadają zdolność generowania wartości ekonomicznej. To oznacza, że mogą być nabywane i sprzedawane na rynku. Dlatego też działalności, które prowadzą do wytwarzania takich dóbr, określa się mianem sektora kreatywnego, sektora kultury, przemysłów kreatywnych lub przemysłów kultury¹. Jest to wynik postępującej od połowy XX wieku ekonomizacji kultury, która polega na tym, że zjawiskom kulturalnym przypisuje się również znaczenie gospodarcze.

Gospodarka kreatywna jest sferą powstającą na styku dwóch części społeczeństwa - gospodarki i kultury. Obie te części mają zgoła odmienną naturę, co sprawia, że zjawiska zachodzące w ich obrębie mają dualny charakter. Artysta, z punktu widzenia kultury, jest twórcą dzieł sztuki, a więc przedmiotów o szczególnych walorach estetycznych i artystycznych. Z punktu widzenia gospodarki - jest on przedsiębiorcą lub pracownikiem,

${ }^{1} \mathrm{~W}$ sprawie relacji między tymi pojęciami i dyskusji terminologicznej zob. K. Stachowiak, Problemy metodologiczne badania sektora kreatywnego, „Rozwój Regionalny i Polityka Regionalna” 2015, nr 30. 
który wytwarza określone dobra, trafiające następnie na rynek i nabywane przez konsumentów. Jest on zatem jednocześnie elementem kultury danego społeczeństwa oraz częścią jego systemu gospodarczego. W zależności od sytuacji przejawia inne cechy. To sprawia, że gospodarka kreatywna charakteryzuje się dualizmem ekonomiczno-kulturowym ${ }^{2}$, dlatego też elementy tej gospodarki przejawiają, w zależności od sytuacji, własności ekonomiczne lub kulturowe.

W gospodarce kreatywnej funkcjonują podmioty, które - niezależnie od ich formy organizacyjnej - są aktywnymi uczestnikami procesów gospodarczych, a ich decyzje i działania wywołują skutki ekonomiczne. Dualistyczny, ekonomiczno-kulturowy charakter gospodarki kreatywnej sprawia, że podmioty te funkcjonują również w sferze kultury. David Throsby do głównych kategorii podmiotów w gospodarce kreatywnej zalicza między innymi: pracowników kultury (zarówno twórców, jak i personel pomocniczy lub administracyjny), firmy prywatne (nastawione na zysk), prywatne organizacje nienastawione na zysk (non-profit), publiczne instytucje kultury, szkoły artystyczne, agencje rządowe i samorządowe związane z kulturą czy organizacje międzynarodowe, takie jak UNESCO, a także konsumentów lub odbiorców kultury ${ }^{3}$. W zależności od struktury gospodarki danego regionu czy kraju, a także od specyfiki kultury, wyżej wymienione podmioty będą odgrywać różną rolę. W rozwiniętych gospodarczo i instytucjonalnie krajach pomiędzy twórcami a odbiorcami tworzy się cały system złożonych powiązań, w których pośredniczą organizacje pozarządowe, firmy prywatne czy też instytucje kultury. Mogą one też pełnić odmienne role, na przykład instytucje kultury mogą pełnić rolę redystrybucyjną, gdy decydują o tym, na które przedsięwzięcia kulturalne zostaną przeznaczone środki publiczne (tak jak robi to Polski Instytut Sztuki Filmowej w przypadku kinematografii). To stawia je jednak w roli producenta - dokonują one alokacji środków, oceniając przy tym wartość kulturową przedsięwzięcia. W niektórych przypadkach instytucje kultury mogą pełnić rolę twórców, jeśli angażują się w proces twórczy. Wydaje się zatem, że zamiast tworzyć listę wszelkich możliwych rodzajów podmiotów, lepiej jest określić je przez pryzmat roli,

2 K. Stachowiak, Gospodarka kreatywna i mechanizmy jej funkcjonowania. Perspektywa geograficzno-ekonomiczna, Poznań 2017.

3 D. Thorsby, The Economics of Cultural Policy, New York 2010, s. 23-24. 
jaką pełnią. Ta bowiem pozwala wyznaczyć ich miejsce w gospodarce. Zatem z punktu widzenia głównych procesów gospodarczych, a więc produkcji, konsumpcji i dystrybucji, a także ze względu na rolę w wytwarzaniu i przekazywaniu wartości kulturowej i ekonomicznej, głównymi rodzajami podmiotów w gospodarce kreatywnej są: (1) twórcy i producenci, (2) odbiorcy oraz (3) pośrednicy kulturowi. O ile dwie pierwsze grupy podmiotów były przedmiotem wielu badań, to znaczenie pośredników kulturowych zostało dostrzeżone względnie niedawno. Im zostanie zatem poświęcona uwaga w niniejszym artykule. Przedstawię główne ujęcia mówiące o tym, kim są pośrednicy kulturowi, a następnie ukażę ich rolę jako selekcjonerów (gatekeepers) w gospodarce kreatywnej.

\section{KIM SĄ POŚREDNICY KULTUROWI? PRZEGLĄD GŁÓWNYCH UJĘĆ}

Pośrednicy kulturowi są specyficzną i niezwykle istotną kategorią podmiotów w gospodarce kreatywnej. Pełnią oni kluczową rolę, zwłaszcza w rozpowszechnianiu dóbr kreatywnych, oraz stanowią swego rodzaju pomost pomiędzy twórcami i producentami a odbiorcami i konsumentami. Pomost ten ma jednak dość swoisty charakter. W tradycyjnej gospodarce główną rolą pośredników jest kojarzenie sprzedających i kupujących. Pośrednicy wiązani są najczęściej z takimi formami działalności, jak agencje zatrudnienia, pośrednictwo finansowe, ubezpieczeniowe czy obrót nieruchomościami. Pośrednicy kulturowi natomiast nie tylko biorą udział w kojarzeniu sprzedających z kupującymi, przez co ułatwiają obieg dóbr, ale ponadto są zaangażowani w kształtowanie ostatecznej wartości dobra. Chodzi tu przede wszystkim o jego wartość kulturową, która jest sumą wartości semiotycznych (w tym symbolicznych), estetycznych, artystycznych, historycznych i autentyczności ${ }^{4}$. Pośrednicy kulturowi są więc ogniwem w łańcuchu wartości, który dodaje coś do już istniejącego dobra. Trudno ich jednoznacznie przyporządkować do któregoś z głównych procesów zachodzących w gospodarce - choć pośredniczą między twórcami a odbiorcami, a więc odgrywają rolę w dystrybucji dóbr kreatywnych, to ich działania obejmują bardzo często sferę produkcyjną, a nawet i konsumpcyjną. Sytuacji nie ułatwia

4 Por. D. Throsby, Ekonomia i kultura, tłum. O. Siara, Warszawa 2010, s. 39-40. 
fakt, że pojęcie „pośrednicy kulturowi” jest nie do końca określone: w literaturze pojawia się ono w trzech głównych znaczeniach, jako: (1) jednostki lub grupy pełniące rolę medium pomiędzy kulturami, (2) zbiór profesji, których zadaniem jest transfer wartości kulturowych w społeczeństwie, (3) jednostki lub grupy zaangażowane w transfer dóbr kreatywnych i wartości kulturowych pomiędzy twórcami a odbiorcami.

W pierwszym $\mathrm{z}$ wymienionych znaczeń pośrednik kulturowy stanowi łączące ogniwo lub medium pomiędzy różnymi grupami kulturowymi, na przykład między kulturami narodowymi, grupami etnicznymi itp. Rola pośredniczenia związana jest z przenoszeniem treści lub wartości kulturowych z jednej kultury na inną. Taki pośrednik zna i rozumie oba konteksty kulturowe i w pewnym sensie tłumaczy jedne treści na drugie. Przykładem może być imigrant, który przebywa w innej niż swoja rodzima kulturze na tyle długo, że swobodnie posługuje się językiem oraz szeregiem innych kodów kulturowych. Wartości i postawy charakterystyczne dla rodzimej kultury są dzięki temu transferowane do miejsca aktualnego pobytu, a więc do innej kultury. Analogicznie transfer ten może odbywać się w drugą stronę - imigranci tacy przyjmują pewne wartości i postawy od otoczenia, w którym przebywają. David B. Ruderman i Giuseppe Veltri analizowali w ten sposób rolę żydowskich intelektualistów w kształtowaniu się renesansu we Włoszech ${ }^{5}$. Pojęcie pośredników kulturowych w tym znaczeniu jest jednak stosunkowo rzadko używane w badaniach społecznych ${ }^{6}$.

Drugie znaczenie tegoż pojęcia związane jest z pracami Pierre’a Bourdieu, a zwłaszcza z jego dziełem Dystynkcja. Społeczna krytyka władzy sądzenia. Zawiera ono fragmenty omawiające nowe profesje, które pojawiły się w społeczeństwach XX-wiecznych, a ich zadaniem była mediacja między wytworami sztuki i kultury a masami, w trakcie której zmianie ulega forma i ranga społeczna tych wytworów. Choć nie sposób w kilku zdaniach streścić złożonej koncepcji Bourdieu, to główne przesłanie Dystynkcji można sprowadzić do twierdzenia, że uczestnictwo

5 Cultural Intermediaries: Jewish Intellectuals in Early Modern Italy, ed. D.B. Ruderman, G. Veltri, Philadelphia 2004.

6 V. Durrer, S. Miles, New Perspectives on the Role of Cultural Intermediaries in Social Inclusion in the UK, „Consumption Markets and Culture” 2009, Vol. 12, No. 3. 
w kulturze jest uwikłane w różnice między klasami społecznymi, a zatem występuje zbieżność uwarstwienia społecznego i kulturowego, w związku z czym zróżnicowanie społeczne pokrywa się z wyborami kulturowymi ${ }^{7}$. Naturalnymi konsumentami kultury wysokiej są elity społeczne, natomiast klasy niżej usytuowane pozostają w kręgu oddziaływania kultury wytwarzanej na skalę masową. „Powoduje to, że określona ranga społeczna znajduje swe odzwierciedlenie w kulturowej wartości konsumowanych dóbr i podejmowanych praktyk. Pozycja w hierarchii społecznej pozostaje zatem w ścisłym związku z pozycją hierarchicznie uporządkowanych pod względem prawomocności wyborów kulturowych"8. W takiej sytuacji dość widoczne są również zależności między „kapitałem edukacyjnym” a „kapitałem kulturowym”. Ci, którzy odwiedzają muzea i galerie sztuki lub potrafią rozpoznać klasycznych kompozytorów - a więc są w stanie właściwie odebrać i uczestniczyć w „kulturze prawomocnej” - mają najczęściej lepsze wykształcenie. Stanowią oni mniejszość, i w konsekwencji większa część społeczeństwa nie jest w stanie w owej kulturze partycypować. W związku z tym w drugiej połowie XX wieku pojawiły się nowe zawody - w tym pośrednicy kulturowi - będące częścią „nowego drobnomieszczaństwa”. Pozwalają one na tworzenie „kultury średniej”, która, najogólniej rzecz ujmując, jest spopularyzowaną i uproszczoną wersją „kultury prawomocnej”, dostępnej dzięki tym procesom dla liczniejszej publiczności. „Kultura średnia zawdzięcza część swojego powabu wszystkim odniesieniom do kultury prawomocnej, które zawiera i które skłaniają i dają podstawę do utożsamiania jej z tamtą kulturą"'. Takie odniesienia to przystępne adaptacje filmowe klasycznych dzieł literackich, popularne aranżacje muzyki klasycznej, „pozornie wyrafinowane orkiestracje ludowych przyśpiewek” czy wokalne interpretacje klasycznych dzieł. Bourdieu następująco wyjaśnia, w jaki sposób taka kultura jest tworzona i rozpowszechniana:

7 P. Bourdieu, Dystynkcja. Społeczna krytyka władzy sądzenia, tłum. P.P. Bilot, Warszawa 2000.

8 K. Strzyczkowski, Szlachectwo nie zobowiazuje. Zmiany we wzorach konsumpcji kulturowej, „Ruch Prawniczy, Ekonomiczny i Socjologiczny” 2009, z. 1, s. 196.

9 P. Bourdieu, op. cit., s. 396. 
Nowi pośrednicy kulturowi (do najbardziej typowych należą redaktorzy programów kulturalnych w radiu lub telewizji, krytycy z dzienników i tygodników „dbających o poziom” oraz wszyscy dziennikarze-pisarze i pisarze-dziennikarze), stawiając czoło podwójnej konkurencji producentów, czyli auctores, i prawomocnych komentatorów, czyli lectores - w starciu z którymi nie mieliby szans, gdyby nie dysponowali specyficzną mocą, jaką gwarantuje opanowanie mass mediów - wymyślili całą serię gatunków pośrednich między kulturą prawomocną a produktami masowymi („felietony”, „eseje”, „świadectwa" itd. $)^{10}$.

Jak widać, pośrednicy kulturowi mają tu zupełnie inny charakter niż w pierwszym znaczeniu tego pojęcia. Po pierwsze, kultura prawomocna, o której tu mowa, związana jest z działalnością artystyczną i sztuką, jak na przykład literatura, muzyka czy sztuki sceniczne. Po drugie, mediacja ma charakter jednokierunkowy - od kultury prawomocnej do określonych odbiorców, nie odwrotnie. Po trzecie, istnieje istotna różnica w wielkości „populacji”, między którymi usytuowani są pośrednicy, bowiem Bourdieu często wskazuje na masowe media i masową produkcję. Zatem pośrednicy kulturowi „tłumaczą” w relacji niewielu-do-wielu: od niewielkiej grupy twórców do znacznie większej rzeszy odbiorców. Przy okazji Bourdieu podaje konkretne zawody, które zaliczane są do kategorii pośredników kulturowych, pisząc, że:

Nowe drobnomieszczaństwo spełnia się w zawodach prezentacji i reprezentacji (takich jak przedstawiciele handlowi, specjaliści od reklamy, public relations, mody, dekoracji itd.) oraz we wszelkich instytucjach sprzedaży dóbr i usług symbolicznych, czy będą to zawody z zakresu pomocy medyczno-społecznej (tacy jak doradcy do spraw małżeńskich, seksuolodzy, dietetycy, doradcy z poradni zawodowych i dziecięcych itd.), czy też produkcji i animacji kultury (animatorzy kulturalni, pedagodzy, reżyserzy oraz prezenterzy radiowi i telewizyjni, dziennikarze w czasopismach itd.), których szybko przybywało w ciągu ostatnich lat ${ }^{11}$.

Nazywa ich też „handlarzami potrzeb, sprzedawcami dóbr i usług symbolicznych, którzy sprzedają zawsze samych siebie jako typowych

10 Ibidem, s. 397.

${ }^{11}$ Ibidem, s. 439. 
reprezentantów i gwarantów wartości swoich produktów, i tak skutecznie pełnią funkcję reprezentacji tylko dlatego, że prezentują dobrze i wierzą w wartość tego, co prezentują i reprezentują"12.

Jennifer Smith Maguire i Julian Matthews zwracają uwagę, że choć pojęcie pośredników kulturowych odgrywa relatywnie niewielką rolę w analizach Bourdieu, to zyskało ono wagę w anglosaskich koncepcjach socjologicznych ${ }^{13}$. Rozszerzono w nich znacznie zakres pojęcia, co przyczyniło się do wyłonienia trzeciego znaczenia pośredników kulturowych, zgodnie $\mathrm{z}$ którym są to podmioty zaangażowane w transfer wartości kulturowych, zwłaszcza pomiędzy twórcami a odbiorcami, ale także w wewnętrznym polu samych twórców lub samych odbiorców. Owo rozszerzenie zakresu sprawiło, że pojęcie pośredników kulturowych stało się - według Davida Hesmondhalgha - jednym $\mathrm{z}$ bardziej niejasnych ${ }^{14}$, tym bardziej że wynikało ono z dość luźnych, a czasem niewłaściwych interpretacji idei Bourdieu ${ }^{15}$. Można też powiedzieć, że uległo ono dekontekstualizacji, w efekcie czego $\mathrm{w}$ użyciu pozostał sam termin, a jego oryginalne znaczenie zostało zmienione lub zastąpione nowym. Dla wielu badaczy może mieć to uzasadnienie praktyczne, ponieważ kategoria pośredników kulturowych jest użyteczna analitycznie, a przez nadanie jej zmienionego lub nowego znaczenia pozwala na zdystansowanie się od lewicująco-krytycznej proweniencji myśli Bourdieu. Według Hesmondhalgha to nowe znaczenie uformowało się na początku lat 90. XX wieku. W znanej i wpływowej w kręgach anglojęzycznych pracy na temat sfery produkcyjnej w kulturze - Production of Culture / Cultures of Production pod redakcją Paula du Gaya - jeden z jej autorów, Sean Nixon, określił mianem pośredników kulturowych praktycznie wszystkie podmioty włączone w obieg wartości i dóbr kulturowych: są nimi wszystkie te osoby lub organizacje, które przenoszą znaki i ich znaczenia, lub szerzej:

12 Ibidem, s. 446.

13 J. Smith Maguire, J. Matthews, Bourdieu on Cultural Intermediaries, [w:] The Cultural Intermediaries Reader, red. J.S. Maguire, J. Matthews, London 2014.

14 D. Hesmondhalgh, The Cultural Industries. Sage, London 2002, s. 53.

15 Ibidem, s. 54; K. Negus, The Work of Cultural Intermediaries and the Enduring Distance between Production and Consumption, „Cultural Studies” 2002, Vol. 16, No. 4, s. 502. 
wartość kulturową, z jednego miejsca w drugie ${ }^{16}$. Dla Nixona, podobnie zresztą jak dla Bourdieu, najbardziej reprezentatywnym przykładem pośrednictwa kulturowego jest branża reklamowa, której znaczenie i udział w rynku globalnym istotnie wzrosły w XX wieku. Reklama jest tą częścią komunikacji, która ma dostarczać informacji w formie perswazyjnej na temat dóbr dla potencjalnych odbiorców lub klientów. Operuje w tym celu szerokim zestawem znaków i kodów kulturowych, często mocno uwikłanych w sieci znaczeniowe funkcjonujące w społeczeństwie. Jest przy tym łącznikiem między sprzedającym a potencjalnym kupującym. Jak widać, w odróżnieniu od poprzednich dwóch znaczeń, takie pośrednictwo kulturowe nie jest ani pomostem między kulturami, ani też między kulturą prawomocną a popularną, ale stanowi raczej kanał transmisji niemal każdej z możliwych form kulturowych. Ze względu na nader szeroki zakres pojęcia pośrednika kulturowego Hesmondhalgh sugeruje, żeby porzucić używanie tego niejasnego terminu na rzecz bardziej konkretnych określeń, takich jak „menedżer kreatywny”, „twórca symboli” lub „kreatywny praktyk”.17.

Niezależnie od problemów z klarownością pojęcia, trudno kwestionować rolę pośredników kulturowych we współczesnej gospodarce kreatywnej. W pracy na temat roli przedsiębiorczości w sektorze kultury ${ }^{18}$ Charlie Leadbeater i Kate Oakley w następujący sposób charakteryzują znaczenie pośredników kulturowych dla gospodarki kreatywnej:

Są oni niezbędni do tego, aby wypełnić „dziurę” w strukturze sektora kreatywnego. Pośrednicy kulturowi odkrywają i promują talenty, wprowadzają do obiegu idee i trendy, kontaktują ludzi ze sobą, organizują wydarzenia oraz umożliwiają dostęp do rynku. Pośrednicy kulturowi są często twórcami, którzy zostawili działalność twórczą za sobą i poszli dalej w innym kierunku. Są nimi piosenkarze, którzy zostali menedżerami; aktorzy, którzy zostali łowcami

${ }^{16}$ S. Nixon, Circulating Culture, [w:] Production of Culture / Cultures of Production, red. P. du Gay, London 1997, s. 181.

17 D. Hesmondhalgh, op. cit., s. 53.

18 Warto nadmienić, że praca ta miała istotny wpływ na kształtowanie się polityki rozwoju sektora kreatywnego w Wielkiej Brytanii pod koniec lat 90., a w szczególności na raporty i dokumenty opracowywane przez brytyjskie Ministerstwo Kultury, Mediów i Sportu (DCMS), które później stały się wzorem dla podobnych opracowań w innych krajach. 
talentów; twórcy programów telewizyjnych, którzy zostali redaktorami w wydawnictwach. Są niczym olej w trybach sektora kreatywnego. W Dolinie Krzemowej tę rolę [...] odgrywa kapitał wysokiego ryzyka. Pośrednicy kulturowi są co prawda mniej sformalizowani i mniej wpływowi niż ich odpowiednicy z Doliny Krzemowej, jednak podobnie jak oni sprawiają, że wszystko się kręci. W gruncie rzeczy to oni umieszczają lokalne talenty na szerszym, komercyjnym rynku. Aby sektor kreatywny mógł skutecznie się rozwijać, potrzebuje nie tylko zdolnych twórców, ale również skutecznych pośredników. Promowanie tych pośredników powinno być celem polityki publicznej ${ }^{19}$.

Widać tu rolę pośredników kulturowych jako połączeń w łańcuchu produkcji kulturowej, ze znacznym podkreśleniem ich znaczenia gospodarczego i możliwości generowania wartości ekonomicznych dzięki ich działalności. Znaczenie pośredników polega zatem na dostarczaniu środków, za pomocą których można tworzyć dobra rynkowe z działalności kulturowej. Łączą oni zatem artefakty kulturowe z rynkiem, co oznacza, że wytwory kultury mogą być kupowane i sprzedawane oraz mogą przynosić zysk ich twórcom. Jednakże, co bardzo ważne, pośrednicy kulturowi nie pełnią tylko prostej, logistycznej roli dostarczycieli produktów na rynek. Biorą oni bowiem udział nie tyle w obiegu dóbr, ile wartości kulturowych - bazują na semiotycznych kodach kulturowych, nierzadko modyfikując je i dostosowując do wymagań rynku. Zatem to kompetencje kulturowe, jak i znajomość realiów ekonomicznych pozwalają im odgrywać tę gospodarczą rolę.

Znaczenie pośredników kulturowych dla gospodarki kreatywnej oraz specyfika ich działania były przedmiotem licznych badań, z których każde podkreślało ich fundamentalny charakter dla obiegu wartości kulturowych i dóbr kreatywnych ${ }^{20}$. Chris Gibson uważa, że także nauka i uczeni pełnią

${ }_{19}$ Charles Webster Leadbeater, Kate Oakley, The Independents: Britain's New Cultural Entrepreneurs, London 1999, s. 45.

20 K. Negus, op. cit.; D. Wright, Mediating Production and Consumption: Cultural Capital and 'Cultural Workers', „The British Journal of Sociology” 2005, Vol. 56, No. 1; L. De Propris, S. Mwaura, Demystifying Cultural Intermediaries: Who Are They, What Do They Do and Where Can They Be Found in England?, Discussion Paper 2013-07, Birmingham 2013; J. Smith Maguire, J. Matthews, op. cit.; D. Jakob, B. van Heur, Taking Matters into Third Hands: Intermediaries and the Organization of the Creative Economy, „Regional Studies” 2015, Vol. 49, No. 3; J. O'Connor, Intermediaries and 
rolę pośredników kulturowych - badając sektor kreatywny i procesy w nim zachodzące, wytwarzają wiedzę, która potem jest transferowana do społeczeństwa poprzez publikacje czy wykłady. Ponadto pełnią oni również często rolę ekspertów, pomagając kształtować politykę publiczną. W tym edukacyjnym i eksperckim wymiarze stają się „promotorami” gospodarki kreatywnej ${ }^{21}$. Zatem w tym sensie również i ten tekst oraz jego autor pełnią rolę pośrednika kulturowego.

Norma Rantisi i Deborah Leslie wskazują ponadto, że edukacja w ogóle ma charakter pośredniczący i pozwala nie tylko funkcjonować gospodarce kreatywnej, ale i ją rozwijać. System szkolnictwa artystycznego jest przecież istotnym ogniwem w obiegu nie tylko wiedzy, ale i wartości kulturowych ${ }^{22}$. $\mathrm{W}$ rozwiniętych społeczeństwach ma on rozbudowany i wyspecjalizowany charakter. Przykładowo w kanadyjskim Montrealu funkcjonuje od 1981 roku Narodowa Szkoła Cyrkowa (École Nationale de Cirque), która ma status państwowej szkoły wyższej. Montrealska szkoła jest zapleczem dla rozwiniętej w tym mieście sztuki cyrkowej, a zwłaszcza dla światowej sławy przedsięwzięcia - Cirque du Soleil, powstałego w 1984 roku. Cirque du Soleil jest specyficznym połączeniem sztuki ulicznej i biznesu. O skali przedsięwzięcia niech świadczy fakt, że przy tworzeniu widowisk pracuje ponad cztery tysiące osób z ponad czterdziestu krajów, przychody przekraczają 810 milionów USD rocznie, a marża (zysk) jest szacowana na ponad 20 procent $^{23}$. W Polsce również funkcjonuje podobna szkoła artystyczna - Państwowa Szkoła Sztuki Cyrkowej w Julinku, nieopodal Warszawy, która kontynuuje tradycje szkoły cyrkowej założonej w latach 60. XX wieku.

Imaginaries in the Cultural and Creative Industries, „Regional Studies” 2015, Vol. 49, No. 3; C. Taylor, Between Culture, Policy and Industry: Modalities of Intermediation in the Creative Economy, „Regional Studies” 2015, Vol. 49, No. 3.

${ }^{21}$ Ch. Gibson, Negotiating Regional Creative Economies: Academics as Expert Intermediaries Advocating Progressive Alternatives, „Regional Studies” 2015, Vol. 49, No. 3, s. 477.

${ }^{22}$ N. Rantisi, D. Leslie, Significance of Higher Educational Institutions as Cultural Intermediaries: The Case of the École Nationale de Cirque in Montreal, Canada, „Regional Studies” 2015, Vol. 49, No. 3.

${ }_{23}$ G. Collins, Run Away to the Circus? No Need. It's Staying Here, „The New York Times" 28.04.2009 r., s. C1. 
Obok edukacji rolę pośredników kulturowych pełnią całe branże kreatywne, takie jak reklama ${ }^{24}$ czy branża medialna $^{25}$, lub jej części, jak dziennikarstwo ${ }^{26}$. Ale też w konkretnych działalnościach kreatywnych wiele osób lub organizacji realizuje funkcje pośrednictwa kulturowego, czego przykładem są: agencje talentów w branżach filmowej, muzycznej lub w sztukach scenicznych $^{27}$, regionalne komisje filmowe w branży filmowej ${ }^{28}$, niezależni rzemieślnicy artystyczni ${ }^{29}$, projektanci mody ${ }^{30}$ czy wzornictwa przemysłowego ${ }^{31}$. Pośrednicy kulturowi są kluczowymi ogniwami w branżach o wysoce rozwiniętych i złożonych sieciach produkcji, takich jak branża filmowa ${ }^{32}$

${ }^{24}$ L. McFall, What About the Old Cultural Intermediaries? An Historical Review of Advertising Producers, „Cultural Studies” 2002, Vol. 16, No. 4; C. Hodges, „PRP Culture": A Framework for Exploring Public Relations Practitioners as Cultural Intermediaries, „Journal of Communication Management” 2006, Vol. 10, No. 1; L. Moor, Branding Consultants as Cultural Intermediaries, "The Sociological Review” 2008, Vol. 56, No. 3.

25 D. Hesmondhalgh, Bourdieu, the Media and Cultural Production, „Media, Culture \& Society" 2006, Vol. 28, No. 2; J.S. Maguire, J. Matthews, Cultural Intermediaries and the Media, „Sociology Compass” 2010, Vol. 4, No. 7.

${ }^{26}$ K. Negus, The Production of Culture, [w:] Production of Culture / Cultures of Production, op. cit.

27 F. Martel, Mainstream. Co podoba się wszędzie na świecie, tłum. K. Sikorska, Warszawa 2010, s. 114-122.

28 P. Foster, St. Manning, D. Terkla, The Rise of Hollywood East: Regional Film Offices as Intermediaries in Film and Television Production Clusters, „Regional Studies" 2015, Vol. 49, No. 3.

${ }_{29}$ B. Shultz, The Work Behind the Scenes: The New Intermediaries of the Indie Crafts Business, „Regional Studies” 2015, Vol. 49, No. 3.

${ }_{30}$ L. Skov, Hong Kong Fashion Designers as Cultural Intermediaries: Out of Global Garment Production. „Cultural Studies” 2002, Vol. 16, No. 4.

31 T. Vinodrai, Constructing the Creative Economy: Design, Intermediaries and Institutions in Toronto and Copenhagen. „Regional Studies” 2015, Vol. 49, No. 3.

32 A.J. Scott, On Hollywood: The Place, the Industry, Princeton 2005; L. De Propris, L. Hypponen, Creative Clusters and Governance: The Dominance of the Hollywood Film Cluster, [w:] Creative Cities, Creative Clusters and Local Economic Development, red. P. Cooke, L. Lazzeretti, Cheltenham 2007. 
oraz muzyczna ${ }^{33}$. Co interesujące, w tej ostatniej, pomimo rosnącej digitalizacji produkcji muzycznej i popularności wirtualnych pośredników, takich jak YouTube, to raczej realni niż wirtualni pośrednicy okazują się istotni, jeśli myśli się o przynajmniej minimalnym powodzeniu komercyjnym ${ }^{34}$. Niektórzy autorzy wskazują na to, że nawet konsumenci mogą pełnić rolę pośredniczącą. Przykładem jest tu japońska manga, której fani podejmują się tłumaczenia, redakcji i rozpowszechniania tej formy komiksu poza Japonią, bez oficjalnej zgody właścicieli praw autorskich ${ }^{35}$. Zasadne staje się zatem pytanie, które stawiają Maguire i Matthews: czy aby wszyscy nie jesteśmy już pośrednikami kulturowymi?

Pozytywna odpowiedź na powyższe pytanie skutkować będzie nadmiernym rozszerzeniem rozumienia tego, kim są pośrednicy kulturowi. W związku z tym proponuję uściślenie tego pojęcia i ograniczenie go do dwojakiego pojmowania:

1) Pośrednictwo kulturowe jako rola, która polega na pośredniczeniu w obiegu wartości kulturowej (szersze ujęcie). Ta wartość związana jest $\mathrm{z}$ dobrami kreatywnymi, w związku z czym często jest to pośrednictwo w obiegu dóbr. Podmioty pełniące rolę pośredniczącą nie muszą być (i często nie są) w tym pośrednictwie wyspecjalizowane. Role pośrednictwa kulturowego polegają zatem na: (a) kojarzeniu twórców (sprzedających) i odbiorców (kupujących), (b) przekazywaniu wartości kulturowej lub (c) modyfikacji wartości kulturowej. Należy zwrócić uwagę, że rola pośrednictwa kulturowego może mieć zarówno intencjonalny, jak i przypadkowy charakter. Metaforycznie można ją porównać do roli pszczoły, która zbiera pyłek z jednych roślin, przenosi je na inne i je zapyla. O ile pszczoły robią to wyłącznie instynktownie, o tyle działania pośredników kulturowych są często celowe.

33 P. Gałuszka, Biznes muzyczny. Ekonomiczne i marketingowe aspekty fonografii, Warszawa 2009; A. Watson, Cultural Production in and beyond the Recording Studio, London 2015.

34 B.J. Hracs, Cultural Intermediaries in the Digital Age: The Case of Independent Musicians and Managers in Toronto, „Regional Studies” 2015, Vol. 49, No. 3.

35 H.-K. Lee, Cultural Consumers as "New Cultural Intermediaries”: Manga Scanlators, „Arts Marketing: An International Journal” 2012, Vol. 2, No. 2. 
2) Pośrednik kulturowy jako wyspecjalizowany podmiot (węższe ujęcie) - może być nią jednostka (osoba) lub organizacja (np. firma, organizacja pozarządowa) wyspecjalizowana w takiej działalności, dla której pośrednictwo kulturowe jest jednym z głównych obszarów działania lub który stanowi dla niej źródło utrzymania bądź dochodu.

Tak określeni pośrednicy mogą działać we wszystkich głównych procesach gospodarczych (produkcja, dystrybucja, konsumpcja), przy czym ich główna rola związana jest z produkcją i dystrybucją. Działalność pośredników kulturowych może mieć charakter rynkowy, gdy jest to działalność nastawiona na zysk (np. agencje talentów), lub nierynkowy - w przypadku gdy ma ona charakter autoteliczny, związany z realizacją misji społecznych lub innych wartości ogólnych (np. szkoły artystyczne, fani).

\section{POŚREDNICY KULTUROWI JAKO SELEKCJONERZY (GATEKEEPERS)}

Pojęcie selekcji (gatekeeping) funkcjonuje w naukach społecznych od końca lat 40. XX wieku, kiedy to psycholog społeczny Kurt Lewin uznał na podstawie swoich badań, że we wszelkich sytuacjach społecznych przepływ informacji jest zawsze nierównomierny i niecałkowity ${ }^{36}$. Przepływ ten reguluje cała seria barier, nazywanych bramami (gates), które są kontrolowane przez określone jednostki lub organizacje pełniące rolę selekcjonerów (gatekeepers), przepuszczających pewne informacje, a zatrzymujących inne. $\mathrm{W}$ tym rozumieniu selekcja jest więc procesem zmniejszania ogromnej ilości informacji i przekształcania ich w ograniczoną liczbę wiadomości, które docierają do odbiorców w procesie komunikacji społecznej ${ }^{37}$. W dużych i rozwiniętych społeczeństwach komunikacja kulturowa opiera się w znacznym stopniu na różnego rodzaju mediach, przez co są one centralną częścią współczesnego życia publicznego. Proces selekcji nie tylko określa, które informacje zostaną przekazane odbiorcom, ale także to, jaka jest ich treść. Ponieważ kultura symboliczna w przeważającej mierze ma charakter semiotyczny i związana jest $\mathrm{z}$ tworzeniem, przekazywaniem, odbiorem i interpretacją różnych treści, można proces selekcji takich treści określić

36 T. Goban-Klas, Media i komunikowanie masowe. Teorie i analizy prasy, radia, telewizji i Internetu, Warszawa 2001 s. 58-59.

37 P.J. Shoemaker, T.P. Vos, Gatekeeping Theory, New York 2009, s. 1. 
mianem selekcji kulturowej. Obejmuje ona filtrowanie i przekształcanie treści oraz ich przesyłanie za pomocą odpowiednich mediów lub kanałów.

W odniesieniu do sektora kultury, a zwłaszcza kultury popularnej, Paul Hirsch zaproponował model produkcji kulturowej, w którym przedstawił między innymi działanie mechanizmu selekcji ${ }^{38}$. Model Hirscha oparty był o jego pionierskie prace dotyczące struktury produkcji w branży muzycznej, w których analizował proces filtrowania i wyboru piosenek lub płyt odnoszących następnie sukces komercyjny ${ }^{39}$ - prace te były później inspiracją w badaniach nad ekonomiką sektora kultury i sektora kreatywnego ${ }^{40}$. Podejście Hirscha czerpało również z rozwijającego się w tym czasie systemowego ujęcia w teorii organizacji i ukazywało produkcję kulturową jako proces, w trakcie którego z ogólnej liczby twórców w kolejnych etapach zostają wybierani nieliczni, których dzieła trafiają w efekcie do konsumentów (ryc. 1). $\mathrm{Na}$ pierwszym etapie pośrednicy kulturowi to osoby lub firmy zajmujące się wyszukiwaniem utalentowanych artystów lub obiecujących twórców i starające się określić ich potencjał kreatywny. Takimi pośrednikami są na przykład agencje talentów, wydawnictwa, wytwórnie płytowe. Oferują one twórcom wsparcie finansowe, pomoc techniczną, sieci dystrybucji i inne zasoby, które posiadają po to, aby wytworzyć określony produkt i dostarczyć go na rynek. Rolę takich selekcjonerów pełnią nawet programy telewizyjne w rodzaju „Mam talent!”.

W kolejnym etapie pojawiają się konsumenci pośredni (surrogate consumers), którzy nabywają gotowy produkt (piosenkę, film lub program telewizyjny), a potem udostępniają go końcowemu odbiorcy. Do tej grupy można zaliczyć stacje radiowe i telewizyjne, wydawnictwa prasy itp. Konsumenci pośredni również dokonują selekcji, tym razem wśród gotowych produktów,

38 P.M. Hirsch, Processing Fads and Fashions: An Organization-Set Analysis of Cultural Industry Systems, „American Journal of Sociology” 1972, Vol. 77, No. 4.

39 P.M. Hirsch, The Structure of the Popular Music Industry: The Filtering Process by which Records are Preselected for Public Consumption, Institute for Social Research, Ann Arbor 1969.

${ }^{40}$ Zob. np. R.E. Caves, Organization of Arts and Entertainment Industries, [w:], Handbook of the Economics of Art and Culture, vol. 1, red. V.A. Ginsburgh, D. Throsby, Amsterdam 2006. Autor szeroko omawia ekonomiczną rolę selekcjonerów w sektorze kreatywnym. 


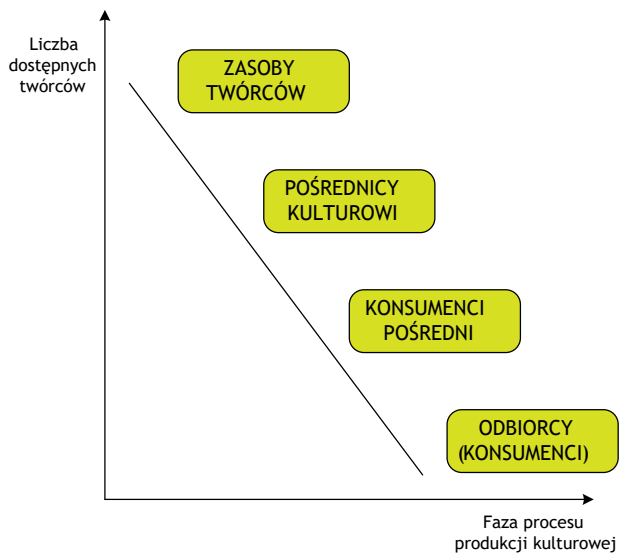

Ryc. 1. Model selekcji kulturowej Hirscha

Źródło: opracowanie własne na podstawie: P.M. Hirsch, Processing Fads and Fashions: An Organization-Set Analysis of Cultural Industry Systems, „American Journal of Sociology"1972, Vol. 77, No. 4.

i udostępniają je do przekazu liczniejszej publiczności. Nie wytwarzają oni zatem dóbr, ale poprzez selekcję wpływają na wartość określonego dobra, tworząc systemy ocen, takie jak listy przebojów, recenzje itp. Odgrywają więc niemałą rolę w łańcuchu wartości dodanej, decydując niekiedy o ewentualnym sukcesie rynkowym lub też porażce danego dobra kreatywnego, albo też wzmacniając pozycję danego dobra, na przykład poprzez częstą emisję piosenki czy filmu. Pełnią oni zatem istotną rolę w ustalaniu końcowej wartości kulturowej dobra kreatywnego, a także wydatnie wpływają na trwałość dóbr kreatywnych ${ }^{41}$. Niekiedy to nie podmioty, ale wydarzenia mają selekcyjny charakter, na co wskazują badania funkcjonowania takich wydarzeń, jak festiwale czy targi, które pełnią rolę „bram” na drodze od twórcy do odbiorcy ${ }^{42}$.

Pomimo szeregu zmian organizacyjnych i technologicznych, jakie zaszły na przełomie wieków w branży muzycznej i innych branżach kreatywnych, model Hirscha jest ciągle aktualny, co pokazał między innymi w swojej

41 Ibidem, s. 274.

42 B. Moeran, J.S. Pedersen, Negotiating Values in the Creative Industries: Fairs, Festivals and Competitive Events, Cambridge University Press, Cambridge 2011. 
pracy Gabriel Rossman. Badał on, w jaki sposób piosenki rozprzestrzeniają się w społeczeństwie (na zasadzie analogii do procesu dyfuzji innowacji), jak zyskują popularność i jaką rolę w tym wszystkim odgrywa radio. Jeden z ważniejszych wniosków z tych badań sprowadza się do wykazania, że pomimo dynamicznego rozwoju mediów cyfrowych w pierwszej dekadzie XXI wieku, tradycyjne radio ciągle pełni kluczową rolę dla muzyków $\mathrm{w}$ ich drodze do komercyjnego sukcesu. Bardzo dobrze przy tym widać rolę mechanizmu selekcji kulturowej, który okazuje się kluczowy dla całej rynkowej branży muzycznej. Rossman zwraca przy tym uwagę, że w produkcji kulturowej owa selekcja ma często charakter bardzo intensywnego odsiewu. Niewielka frakcja aktywnych twórców zostaje zauważona przez pośredników kulturowych, a z grupy tych, którym to się uda, nieliczni są promowani przez konsumentów pośrednich. Lecz nawet z tych, którzy przejdą i ten etap, bardzo niewielu odnosi duży sukces wśród końcowych odbiorców, co zresztą sugerował już Hirsch i co ilustruje stromość linii na zamieszczonej rycinie ${ }^{43}$.

Mechanizm selekcji sprawia, że podmioty, jakimi są selekcjonerzy kulturowi, pełnią kluczową rolę w gospodarce kreatywnej, decydując o tym, które dobra kreatywne zostaną upublicznione i trafią do odbiorców. Z ekonomicznego punktu widzenia selekcjonerzy obniżają koszty transakcyjne związane $\mathrm{z}$ dostępem do informacji na temat jakości dobra oraz jego oceny. Redukują oni również ryzyko i niepewność pojawiające się w różnych etapach łańcucha wartości, związane z oceną tego, który z pomysłów lub realizacji ma szansę na komercyjny sukces ${ }^{44}$. Selekcjonerem, w przypadku branży sztuk plastycznych, może być menedżer galerii sztuki, który decyduje o wystawieniu dzieł wybranych przez siebie artystów. Tę samą rolę pełni również redaktor naczelny w przypadku branży mediów, wybierając artykuły do najnowszego numeru gazety lub wydania programu informacyjnego w radiu lub telewizji. Podobną rolę mogą pełnić nie tylko jednostki, ale również wyspecjalizowane organizacje, takie jak na przykład agencje talentów. Należy mieć jednak na uwadze, że obecnie rola selekcjonerów w branżach kreatywnych zmienia

${ }^{43}$ G. Rossman, Climbing the Charts: What Radio Airplay Tells Us about the Diffusion of Innovation, Princeton 2012.

44 UNDP/UNCTAD, Creative Economy. Report 2010, Geneva - New York 2010, s. 85 . 
się ze względu na rozwój Internetu i mediów cyfrowych, dzięki którym twórcy mają możliwość natychmiastowego publikowania swych dzieł bez udziału pośredników. Służy do tego zestaw różnych narzędzi, jak portale społecznościowe (np. Facebook), portale wideo (np. YouTube), internetowe galerie sztuki (np. Digart) czy blogi ${ }^{45}$. Zarówno intuicja, jak i niektóre głosy w dyskusji ${ }^{46}$ sugerują, że rola mechanizmu selekcji będzie się zmniejszać wraz z upowszechnieniem się Internetu w nowoczesnym społeczeństwie informacyjnym. W myśl tej sugestii Internet pozwala na nieograniczone, bezkosztowe i niemal natychmiastowe udostępnianie dzieł i równie szeroki do nich dostęp. Nie potrzeba zatem podmiotów, które będą wybierały, jakie treści mają znaleźć się w obiegu - to twórcy i odbiorcy sami o tym zadecydują. Tymczasem doświadczenie na to nie wskazuje, a mechanizm selekcji - zamiast zanikać - ciągle jest obecny, choć ewoluuje. Wynikiem owej ewolucji jest wyłanianie się nowego rodzaju selekcji - selekcji technologicznej, która funkcjonuje obok selekcji tradycyjnej. Rolę bramy stanowią w takim przypadku nie bezpośrednio ludzie lub organizacje, ale narzędzia technologiczne, takie jak wyszukiwarki indeksujące treści dostępne za pośrednictwem Internetu. One determinują to, które informacje i w jakiej formie do nas trafiają. Należy przy tym pamiętać, że technologie te są wytworem działalności człowieka i realizują określone przez niego cele. Jak trafnie zauważa Magdalena Szpunar:

Wyszukiwarki kierują się logiką, którą predefiniują jej twórcy. Jest to logika odwołująca się do porządku komercyjnego, zaś rzetelne prezentowanie informacji staje się wtórne wobec generowania zysków. Przypomnijmy, iż wedle badań aż 73\% ankietowanych deklaruje, iż informacje, które wyłuskują dla nich szperacze, są dokładne i wiarygodne, a 66\% uważa, że wyszukiwarki są rzetelnym i obiektywnym źródłem informacji ${ }^{47}$.

45 S. Szultka, Klastry w sektorach kreatywnych - motory rozwoju miast i regionów, Warszawa 2012, s. 44.

${ }^{46}$ P.J. Shoemaker, T.P. Vos, op. cit.; P.-J. Benghozi, Th. Paris, The Cultural Economy in the Digital Age: A Revolution in Intermediation?, „City, Culture and Society" 2016, Vol. 7, No. 2.

${ }^{47}$ M. Szpunar, Wokół koncepcji gatekeepingu. Od gatekeepingu tradycyjnego do technologicznego, [w:] Idee i myśliciele. Medialne i społeczne aspekty filozofi, Kraków 2013, s. 61. 
Według Richarda E. Cavesa selekcjonerzy kulturowi są krytycznym elementem łańcucha wartości w wytwarzaniu prostych dóbr kreatywnych. Wytwarzanie tego rodzaju dóbr angażuje często jednego twórcę i jednego pośrednika kulturowego, który dostosowuje dzieło do wymagań rynku, a potem dystrybuuje dobro do odbiorców, czasem przy pomocy innych pośredników. Ta pozornie prosta relacja niesie jednak ze sobą, według Cavesa, spore wyzwania organizacyjne. Wynika to z trzech powodów. Po pierwsze, na rynku jest wielu twórców, co sprawia, że często mamy do czynienia z ich nadpodażą. Pośrednik kulturowy musi więc pełnić rolę selekcjonera, wybierając jednych i odrzucając innych. Po drugie, łączenie efektów twórczego wkładu artysty z działaniami ekonomicznymi selekcjonera może przybierać różne formy organizacyjne. Podmiot pełniący rolę pośrednika kulturowego może tylko reprezentować twórcę, ale może zawiązać z nim spółkę, przez co uzyska większy wpływ na końcowy kształt dzieła oraz może otrzymać dodatkowe prawa, na przykład do dystrybucji. Wreszcie też może sam zatrudnić artystę i mieć już znaczną kontrolę nad całym procesem twórczym i jego efektami. Po trzecie, lokalizacja działalności kreatywnych ma tendencję do skupiania się. Te tendencje aglomeracyjne zależą jednak od tego, jak relacje między artystą a pośrednikiem kulturowym (selekcjonerem) są zorganizowane i zarządzane. Mechanizm selekcji jest zatem uwikłany w procesy lokalizacyjne ${ }^{48}$.

Ten ostatni element - lokalizacyjny aspekt mechanizmu selekcji kulturowej - wskazuje na konsekwencje przestrzenne procesów funkcjonowania gospodarki kreatywnej. Jak się bowiem okazuje, bliskość geograficzna odgrywa kluczową rolę w budowaniu pozycji twórców, która potem decyduje o ich komercyjnym sukcesie. Chodzi tu przy tym o bliskość względem selekcjonerów oraz społecznych sieci łączących ze sobą twórców i producentów. Elizabeth Currid-Halkett pokazała empirycznie, jaką rolę odgrywa bliskość geograficzna dla procesów budowy reputacji w klastrach kreatywnych Nowego Jorku. Według tej autorki, twórcy doświadczają warunków wysokiej niepewności, zarówno jeśli chodzi o stabilność pracy, jak i przewidywalność popytu na ich dzieła. W tej sytuacji bliskość geograficzna selekcjonerów kulturowych odgrywa kluczową rolę i staje się jednym z głównych czynników

48 R.E. Caves, Organization of Arts and Entertainment Industries, [w:], Handbook of the Economics of Art and Culture, op. cit., s. 537-538. 
lokalizacji w ich otoczeniu - stają się oni swego rodzaju magnesami przyciągającymi twórców. Skoro wartość kulturowa i ekonomiczna dóbr kreatywnych jest przedmiotem ciągłych negocjacji, co jest wynikiem działania mechanizmu obiegu wartości, a jednocześnie selekcjonerzy w dużym stopniu ustalają tę wartość, nie jest zaskakujące, że dla twórców kontakt z takimi selekcjonerami jest decydujący. Co więcej, dzięki tym kontaktom twórcy wspinają się w hierarchii uznania i popularności, co jest kluczowe zarówno dla artystycznego, jak i komercyjnego sukcesu. Selekcjonerzy, pełniąc również rolę swoistych filtrów informacji, mają ogromny wpływ na to, co i jak mówi się o danym twórcy. Według Currid-Halkett, selekcjonerzy kształtują tak zwany lokalny gwar (buzz), a więc obieg plotek, nieformalnych informacji, które składają się na medialny obraz artysty ${ }^{49}$. Również Gina Neff, Elizabeth Wissinger i Sarah Zukin, które badały twórców i pracowników branży mody oraz nowych mediów, podkreślają wagę kontaktów z selekcjonerami kulturowymi. Co najważniejsze, zwracają one uwagę na to, że tymczasowość pracy i efemeryczny charakter reputacji artystycznej czyni te kontakty wręcz przymusowymi dla pracowników kreatywnych. Te czynniki stają się elementami doprowadzającymi do powstawania klastrów kreatywnych. Składają się one bowiem na korzyści aglomeracji związane z tworzeniem więzów zaufania i akumulacji kapitału społecznego ${ }^{50}$. Poza nimi w takich skupieniach występują jeszcze trzy innego rodzaju korzyści. Są to: istnienie wyspecjalizowanego rynku pracy, przepływy wiedzy oraz działanie dużej liczby instytucji otoczenia biznesu ${ }^{51}$. Mechanizm selekcji kulturowej ma więc klastrotwórczy charakter. Potwierdzają to między innymi badania przeprowadzone przez Barbarę Heebels i Irinę van Aalst w dwóch klastrach kreatywnych Berlina: w dzielnicach Prenzlauer Berg i Kreuzberg. Zlokalizowani tam przedsiębiorcy i twórcy podkreślali szczególną rolę selekcjonerów kulturowych w początkowych etapach rozwoju ich działalności. Kontakty z nimi i ich bliskość przestrzenna pozwalały na

49 E. Currid-Halkett, The Warhol Economy: How Fashion, Art, and Music Drive New York City. Princeton University Press, Princeton 2007, s. 130-132.

${ }^{50}$ G. Neff, E. Wissinger, S. Zukin, Entrepreneurial Labor among Cultural Producers: „Cool” Jobs in „Hot” Industries, „Social Semiotics” 2005, Vol. 15, No. 3. 51 K. Stachowiak, P. Tomczak, Przestrzenny wymiar sektora kreatywnego, Poznań 2015 s. 67-70. 
rozwój sieci społecznych oraz na budowę reputacji i marki w miejskich społecznościach kreatywnych. To dzięki obecności selekcjonerów coraz to nowi twórcy byli przyciągani do tych obszarów, co w efekcie spowodowało przekształcenie ich w klaster ${ }^{52}$. Pośrednio mechanizm selekcji ma wpływ także na innowacyjność skupienia, ponieważ selekcja pełni ważną rolę w procesie dyfuzji innowacji ${ }^{53}$. Mechanizm selekcji determinuje, które innowacje zostaną rozprzestrzenione, a które nie. Należy zaznaczyć, że w gospodarce kreatywnej obok klasycznych innowacji produktowych, technologicznych, organizacyjnych lub procesowych, występują również „miękkie innowacje”, a więc na przykład innowacje estetyczne, semiotyczne lub artystyczne ${ }^{54}$. Już Hirsch wskazywał na selekcyjną rolę mediów masowych i nazywał je „instytucjonalnymi regulatorami innowacji"55.

\section{PODSUMOWANIE}

Pośrednicy kulturowi są specyficzną dla gospodarki kreatywnej grupą podmiotów. Ich specyfika polega między innymi na tym, że często współuczestniczą w wytwarzaniu dóbr. Ten udział rzadko jest jednak bezpośredni. Dobra kreatywne powstają jako efekt działalności pojedynczych twórców lub ich grup, a przykładami owych dóbr mogą być: piosenka, powieść, wiersz, obraz, rzeźba czy znak graficzny. Ich wartość jest przede wszystkim funkcją wiedzy, umiejętności, kompetencji, talentu i kreatywności twórców, które stanowią zasoby ich kapitału kulturowego. Wielkość tego kapitału zależy w dużej mierze od edukacji artystycznej lub specjalistycznej. Twórcy z odpowiednim wykształceniem trafiają na rynek, na którym oni lub ich wytwory są zauważane przez tak zwanych pośredników kulturowych. Należą do nich między innymi: agencje talentów, galerie sztuki czy marszandzi, którzy pomagają twórcy zdobyć odpowiednią reputację, dzięki

52 B. Heebels, I. van Alst, Creative Clusters in Berlin: Entrepreneurship and the Quality of Place in Prenzlauer Berg and Kreuzberg, „Geografiska Annaler: Series B, Human Geography” 2010, Vol. 92, No. 4.

53 E.M. Rogers, Diffusion of Innovations, New York 1983, s. 144-145.

54 P. Stoneman, Soft Innovation: Economics, Product Aesthetics, and the Creative Industries, Oxford 2010.

55 P.M. Hirsch, Processing Fads and Fashions: An Organization-Set Analysis of Cultural Industry Systems, „American Journal of Sociology” 1972, Vol. 77, No. 4. 
której rynkowa wartość produkowanych przez niego dóbr będzie wyższa. Oni też często pomagają dystrybuować dobra wytworzone przez twórców. Dlatego też kwalifikacje takich pośredników kulturowych są nie mniej istotne niż kwalifikacje twórców. Zajmują się oni selekcją i często decydują o tym, którzy twórcy lub które wytwory trafią do szerszego obiegu. A od tego zależy często sukces komercyjny na rynku.

\section{Bibliografia}

Pierre-Jean Benghozi, Thomas Paris, The Cultural Economy in the Digital Age: A Revolution in Intermediation?, „City, Culture and Society” 2016, Vol. 7, No. 2, s. 75-80.

Pierre Bourdieu, Dystynkcja. Społeczna krytyka władzy sq̨dzenia, tłum. P.P. Bilot, Wydawnictwo Naukowe „Scholar”, Warszawa 2000.

Richard E. Caves, Creative Industries: Contracts between Art and Commerce, Harvard University Press, Cambridge 2000.

Richard E. Caves, Organization of Arts and Entertainment Industries, [w:], Handbook of the Economics of Art and Culture, vol. 1, red. V.A. Ginsburgh, D. Throsby, Elsevier, Amsterdam 2006, s. 533-566.

Glenn Collins, Run Away to the Circus? No Need. It's Staying Here, „The New York Times" 28.04.2009 r., s. C1.

Elizabeth Currid-Halkett, The Warhol Economy: How Fashion, Art, and Music Drive New York City, Princeton University Press, Princeton 2007.

Lisa De Propris, Laura Hypponen, Creative Clusters and Governance: The Dominance of the Hollywood Film Cluster, [w:] Creative Cities, Creative Clusters and Local Economic Development, red. P. Cooke, L. Lazzeretti, Edward Elgar, Cheltenham 2007, s. 258-286.

Lisa De Propris, Samuel Mwaura, Demystifying Cultural Intermediaries: Who Are They, What Do They Do and Where Can They Be Found in England?, Discussion Paper 2013-07, University of Birmingham, Birmingham 2013.

Victoria Durrer, Steve Miles, New Perspectives on the Role of Cultural Intermediaries in Social Inclusion in the UK, „Consumption Markets and Culture” 2009, Vol. 12, No. 3, s. 225-241.

Pacey Foster, Stephan Manning, David Terkla, The Rise of Hollywood East: Regional Film Offices as Intermediaries in Film and Television Production Clusters, „Regional Studies” 2015, Vol. 49, No. 3, s. 433-450. 
Patryk Gałuszka, Biznes muzyczny. Ekonomiczne i marketingowe aspekty fonografi, Wydawnictwo Placet, Warszawa 2009.

Chris Gibson, Negotiating Regional Creative Economies: Academics as Expert Intermediaries Advocating Progressive Alternatives, „Regional Studies” 2015, Vol. 49, No. 3, s. 476-479.

Tomasz Goban-Klas, Media i komunikowanie masowe. Teorie i analizy prasy, radia, telewizji i Internetu, PWN, Warszawa 2001.

Barbara Heebels, Irina van Aalst, Creative Clusters in Berlin: Entrepreneurship and the Quality of Place in Prenzlauer Berg and Kreuzberg, „Geografiska Annaler: Series B, Human Geography” 2010, Vol. 92, No. 4, s. 347-363.

David Hesmondhalgh, The Cultural Industries, Sage, London 2002.

David Hesmondhalgh, Bourdieu, the Media and Cultural Production, „Media, Culture \& Society" 2006, Vol. 28, No. 2, s. 211-231.

Paul M. Hirsch, The Structure of the Popular Music Industry: The Filtering Process by which Records are Preselected for Public Consumption, Institute for Social Research, University of Michigan, Ann Arbor 1969.

Paul M. Hirsch, Processing Fads and Fashions: An Organization-Set Analysis of Cultural Industry Systems, „American Journal of Sociology” 1972, Vol. 77, No. 4, s. 639-659.

Caroline Hodges, „PRP Culture”: A Framework for Exploring Public Relations Practitioners as Cultural Intermediaries, „Journal of Communication Management" 2006, Vol. 10, No. 1, s. 80-93.

Brian J. Hracs, Cultural Intermediaries in the Digital Age: The Case of Independent Musicians and Managers in Toronto, „Regional Studies” 2015, Vol. 49, No. 3 , s. $461-475$.

Doreen Jakob, Baas van Heur, Taking Matters into Third Hands: Intermediaries and the Organization of the Creative Economy, „Regional Studies” 2015, Vol. 49, No. 3, s. 357-361.

Charles Webster Leadbeater, Kate Oakley, The Independents: Britain's New Cultural Entrepreneurs, Demos, London 1999.

Hye-Kyung Lee, Cultural Consumers as „New Cultural Intermediaries”: Manga Scanlators, „Arts Marketing: An International Journal” 2012, Vol. 2, No. 2 , s. 131-143.

Jennifer Smith Maguire, Julian Matthews, Cultural Intermediaries and the Media, „Sociology Compass” 2010, Vol. 4, No. 7, s. 405-416. 
Jennifer Smith Maguire, Julian Matthews, Are We All Cultural Intermediaries Now? An Introduction to Cultural Intermediaries in Context, „European Journal of Cultural Studies" 2012, Vol. 15, No. 5, s. 551-562.

Jennifer Smith Maguire, Julian Matthews, Bourdieu on Cultural Intermediaries, [w:] The Cultural Intermediaries Reader, red. J.S. Maguire, J. Matthews, Sage, London 2014, s. 15-24.

Frédéric Martel, Mainstream. Co podoba się wszędzie na świecie, tłum. K. Sikorska, Wydawnictwo Czarna Owca, Warszawa 2010.

Liz McFall, What About the Old Cultural Intermediaries? An Historical Review of Advertising Producers, „Cultural Studies” 2002, Vol. 16, No. 4, s. 532-552.

Brian Moeran, Jesper Standgaard Pedersen, Negotiating Values in the Creative Industries: Fairs, Festivals and Competitive Events, Cambridge University Press, Cambridge 2011.

Liz Moor, Branding Consultants as Cultural Intermediaries, „The Sociological Review" 2008, Vol. 56, No. 3, s. 408-428.

Gina Neff, Elizabeth Wissinger, Sarah Zukin, Entrepreneurial Labor among Cultural Producers: „Cool” Jobs in „Hot” Industries, „Social Semiotics” 2005, Vol. 15, No. 3, s. 307-334.

Keith Negus, The Production of Culture, [w:] Production of Culture/Cultures of Production, red. P. du Gay, Sage, London 1997, s. 67-104.

Keith Negus, The Work of Cultural Intermediaries and the Enduring Distance between Production and Consumption, „Cultural Studies” 2002, Vol. 16, No. 4, s. 501-515.

Sean Nixon, Circulating Culture, [w:] Production of Culture/Cultures of Production, red. P. du Gay, Sage, London 1997, s. 177-220.

Justin O'Connor, Intermediaries and Imaginaries in the Cultural and Creative Industries, „Regional Studies” 2015, Vol. 49, No. 3, s. 374-387.

Norma Rantisi, Deborah Leslie, Significance of Higher Educational Institutions as Cultural Intermediaries: The Case of the École Nationale de Cirque in Montreal, Canada, „Regional Studies” 2015, Vol. 49, No. 3, s. 404-417.

Everett M. Rogers, Diffusion of Innovations, Free Press, New York 1983.

Gabriel Rossman, Climbing the Charts: What Radio Airplay Tells Us about the Diffusion of Innovation, Princeton University Press, Princeton 2012.

David B. Ruderman, Giuseppe Veltri (red.), Cultural Intermediaries: Jewish Intellectuals in Early Modern Italy, University of Pennsylvania Press, Philadelphia 2004. 
Allen J. Scott, On Hollywood: The Place, the Industry, Princeton University Press, Princeton 2005.

Pamela J. Shoemaker, Timothy P. Vos, Gatekeeping Theory, Routledge, New York 2009.

Benjamin Shultz, The Work Behind the Scenes: The New Intermediaries of the Indie Crafts Business, „Regional Studies” 2015, Vol. 49, No. 3, s. 451-460.

Lise Skov, Hong Kong Fashion Designers as Cultural Intermediaries: Out of Global Garment Production, „Cultural Studies” 2002, Vol. 16, No. 4, s. 553-569.

Krzysztof Stachowiak, Problemy metodologiczne badania sektora kreatywnego, „Rozwój Regionalny i Polityka Regionalna” 2015, nr 30, s. 9-46.

Krzysztof Stachowiak, Gospodarka kreatywna i mechanizmy jej funkcjonowania.

Perspektywa geograficzno-ekonomiczna, Wydawnictwo Naukowe UAM, Poznań 2017.

Krzysztof Stachowiak, Paulina Tomczak, Przestrzenny wymiar sektora kreatywnego, Bogucki Wydawnictwo Naukowe, Poznań 2015.

Paul Stoneman, Soft Innovation: Economics, Product Aesthetics, and the Creative Industries, Oxford University Press, Oxford 2010.

Konstanty Strzyczkowski, Szlachectwo nie zobowiąuje. Zmiany we wzorach konsumpcji kulturowej, „Ruch Prawniczy, Ekonomiczny i Socjologiczny” 2009, z. 1, s. 195-219.

Magdalena Szpunar, Wokół koncepcji gatekeepingu. Od gatekeepingu tradycyjnego do technologicznego, [w:] Idee i myśliciele. Medialne i społeczne aspekty filo$z o f i$, red. S.I. Fiut, Uczelniane Wydawnictwo Naukowo-Dydaktyczne AGH im. S. Staszica, Kraków 2013, s. 52-61.

Stanisław Szultka (red.), Klastry w sektorach kreatywnych - motory rozwoju miast i regionów, Polska Agencja Rozwoju Przedsiębiorczości, Warszawa 2012.

Calvin Taylor, Between Culture, Policy and Industry: Modalities of Intermediation in the Creative Economy, „Regional Studies” 2015, Vol. 49, No. 3, s. 362-373.

David Throsby, The Economics of Cultural Policy, Cambridge University Press, New York 20102.

David Throsby, Ekonomia i kultura, tłum. O. Siara, Narodowe Centrum Kultury, Warszawa 2010.

UNDP/UNCTAD, Creative Economy. Report 2010, Geneva - New York 2010.

Tara Vinodrai, Constructing the Creative Economy: Design, Intermediaries and Institutions in Toronto and Copenhagen, „Regional Studies” 2015, Vol. 49, No. 3, s. 418-432. 
Allan Watson, Cultural Production in and beyond the Recording Studio, Routledge, London 2015.

David Wright, Mediating Production and Consumption: Cultural Capital and 'Cultural Workers', „The British Journal of Sociology” 2005, Vol. 56, No. 1, s. 105-121.

\section{Cultural Intermediaries and Their Role in the Creative Economy}

The paper presents the role that cultural intermediaries play in creative economy. Cultural intermediaries are a specific and very important category of subjects in the creative economy. They play a key role especially in the dissemination of creative goods. They also serve as intermediaries between creators and producers. However, they are not only involved in connecting sellers with buyers, but are also involved in shaping the final value of goods. Therefore, cultural intermediaries can play a threefold role in the creative economy. They can be: (1) individuals or groups acting as a medium between cultures; (2) a collection of professions to transfer cultural values to society; (3) individuals or groups involved in the transfer of creative and cultural goods, cultural values between creators and audience.

Keywords: cultural intermediaries, creative economy, creative industries 